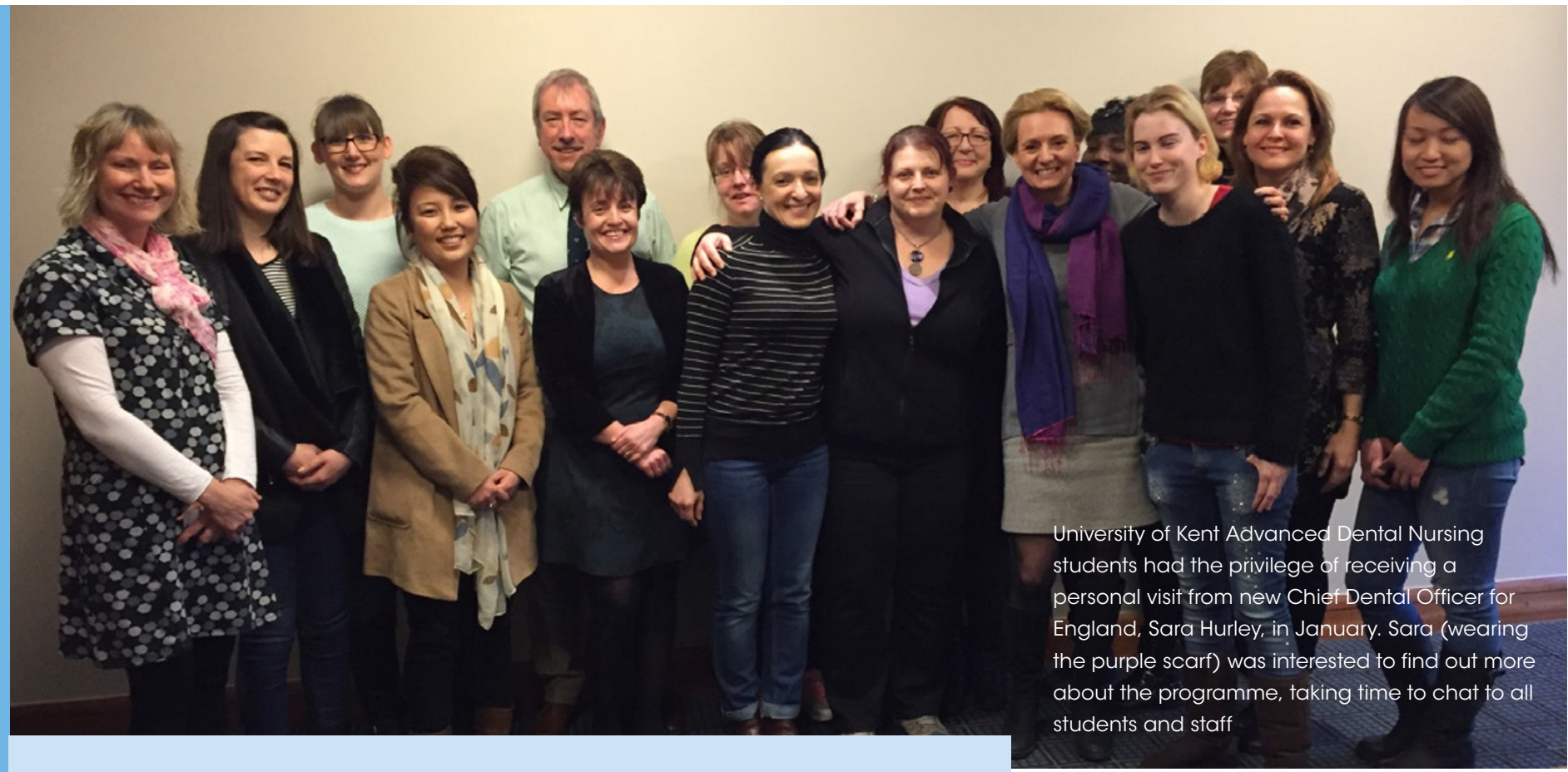

\section{HEKSS HAS LOTS TO OFFER CAREER-MINDED DCPS}

Health Education Kent Surrey and Sussex (HEKSS) is planning to run two PostRegistration Radiography qualifications commencing in May 2016 and is holding their 5th Annual DCP Conference in July 2016. HEKSS will also be running scope of practice courses for DCPs and is recruiting for the Dental Nurse Foundation Degree.

\section{Radiography (Course id 1711 or 1712)}

The NEBDN Certificate in Dental Radiography course will be delivered at The Education Centre at Eastbourne District General Hospital and at The Education Centre at Princess Royal Hospital, Haywards Heath. The course will lead to an examination in March 2017. HEKSS are offering full support from a qualified Dental Nurse Tutor who holds the NEBDN radiography qualification. The theoretical aspect of the course will be delivered using e-learning and classroom sessions and the practical aspect will take place in your own workplace under the supervision of your dentist.

\section{DCP Conference (Course id 1731)}

The theme of this year's conference is 'oral pathology and pharmacology - what do I need to know?', which will take place on Wednesday 13 July at The Charis Centre, Crawley, from 9 am to $5 \mathrm{pm}$. All dental care professionals (DCPs) including dental receptionists and dental practice managers are invited to attend what promises to be an exciting event.

\section{Scope of Practice (Course id 1732)}

HEKSS will commence its 2nd annual training programme for registered dental nurses on the application of fluoride varnish (on prescription) to children and the elderly, in a variety of settings, in April 2016 at The Education Centre, East Surrey Hospital, Redhill.

To book a place on any of the above courses, visit the Dental Education Booking System (DEBS) at www. kssdentaltraining.co.uk and search for the relevant course id number. For any additional information, email team on dentalinfo@kss.hee.nhs.uk.

\section{Foundation Degree in Advanced Dental Nursing}

For dental nurses wishing to enhance their career in dental nursing, this two year course will commence in September 2016, combining home study and 11 threeday contact courses. The course will be provided by HEKSS and validated by the University of Kent. Students are likely to be eligible for tuition fee loans and grants from Student Finance England. For more information and to register your interest, visit www.kssdeanery.ac.uk/foundationdegree-advanced-dental-nursing.

\section{BADT BACKS BAN ON JUNK FOOD ADS BEFORE WATERSHED}

The British Association of Dental

Therapists (BADT) is backing a call for

a ban on junk food adverts screening on television before $9 \mathrm{pm}$.

In January the British Heart Foundation (BHF) called on the Government to introduce a ban on junk food advertising before the watershed as part of the Childhood Obesity Strategy.

The heart charity suggested that loopholes in regulations that mean that food companies can advertise foods high in fat, saturated fat, sugar and salt during popular shows such as 'The X-factor' and 'Hollyoaks' watched by children because current rules only bans them during children's programming. Any adverts falling in adult airtime is accepted.

During the most recent series of The $\mathrm{X}$-factor, the BHF found over 90 adverts for foods high in fat, saturated fat, salt and sugar, such as Cadbury chocolate, Doritos crisps, Kinder chocolate, Chicago Town pizzas and Haribo sweets, all of which are banned during children's programming. 